\title{
Microbiological safety of food of animal origin from organic farms
}

\author{
Maciej Sosnowski ${ }^{\bowtie}$, Jacek Osek \\ Department of Hygiene of Food of Animal Origin \\ National Veterinary Research Institute, 24-100 Puławy, Poland \\ maciej.sosnowski@piwet.pulawy.pl \\ Received: August 13, $2020 \quad$ Accepted: February 16, 2021
}

\begin{abstract}
The organic food sector and consumer interest in organic products are growing continuously. The safety and quality of such products must be at least equal to those of conventional equivalents, but attaining the same standards requires overcoming a particular problem identified in organic food production systems: the occurrence of bacterial pathogens such as Salmonella, Campylobacter, Listeria monocytogenes, Staphylococcus aureus and pathogenic Escherichia coli. These food-borne microorganisms were detected in the production environments of such food. The prevalence of pathogenic bacteria in organic livestock and products may be higher, but may also be the same as or lower than in like material from conventional farms. Furthermore, the incidence of antimicrobial-resistant bacteria was more often detected in conventional than in organic production. The aim of this review was to present the recent information on the microbiological safety of food of animal origin produced from raw materials from organic farms.
\end{abstract}

Keywords: organic food, organic farming, food safety, food-borne pathogens.

\section{Introduction}

In recent years, the organic food sector has been growing continuously in many world regions, especially in the European Union (EU) $(29,32)$. The newest data at the time of writing put 69.8 million hectares under organic agriculture in 181 countries worked by approximately 2.9 million farmers, while in 1999 this area covered 11 million hectares and involved only 200,000 producers. In Europe, 4.4 million bovines, 5.2 million sheep, almost 1 million pigs, and 50 million poultry were reared organically in 2017. Compared to 2008 , increases of $75.8 \%, 73.6 \%, 47.6 \%$, and $103 \%$ were reported, respectively (45). One of the main reasons for changes in consumer habits is the belief that organic products provide health benefits. The safety and quality of such products must be at least equivalent to those of conventional foods, and as consumption of them increases, the potential effect of any safety and quality deficits in organic produce is greater. Livestock in organic agriculture has access to fresh air, and although such a husbandry system is more animal welfare-friendly, it may also create a higher risk of exposure to zoonotic pathogenic agents from the environment $(29,32)$. The main differences between traditional and organic animal husbandry derive from the latter's prioritising ecological principles, and are in housing (lower animal density and access to outdoor areas), feeding (mostly organic feed) and making possible animal expression of natural behaviour (e.g. nesting) (44).

Prophylactic application of antibiotics to animals is not allowed either in conventional or organic production systems. Such preparations are only permitted for use in animal treatment under strict conditions when the use of phytotherapeutic, homeopathic or other products is not possible or ineffective $(8,9)$. However, analysis of food for the presence of antibiotic residues reported that the established acceptable limits have occasionally been exceeded (6, 23). According to Bacanli and Başaran (2), the presence of antimicrobial substances in foodstuffs is growing. Due to specific restrictions on the use of antimicrobials in organic livestock production, there is a higher risk of contamination of such products with bacterial pathogens and consequently an increased microbial hazard. However, the studies in this area are inconsistent (46). Many intestinal bacteria (e.g. Campylobacter, Salmonella, 
and Escherichia coli) that can cause serious diseases in humans do not cause any symptoms in animals. They are part of the commensal intestinal microflora and occur at a relatively high level in the faeces of healthy animals. This is especially important for Shiga toxin-producing E. coli (STEC), including O157, which can induce severe disease in people even when they are present at a very low level $(<100 \mathrm{CFU})$ in food $(14,31)$. The possibility of the occurrence of bacterial pathogens such as Salmonella, Campylobacter, Staphylococcus and pathogenic E. coli has been identified as a particular problem for organic food production systems. Among foods of animal origin, poultry meat and eggs are often associated with the highest risk of food-borne disease, hospitalisation and death in humans. Most infections connected with this food category are caused by Salmonella and Campylobacter. It has been found that pork and pork products are two of the main sources of Salmonella, whereas the most important food-borne pathogens from bovine products are Shiga toxin-producing E. coli strains (31). In the case of dairy farming, Salmonella, Campylobacter, Listeria monocytogenes and Staphylococcus aureus are the major threats besides pathogenic E. coli $(24,25)$.

The microbiological safety of organic food depends on the presence of food-borne microorganisms in the production environment or secondary contamination of the products by these pathogens. Such contamination often occurs during the early stages of primary production (3). The prevalence of pathogenic bacteria in organic livestock and food products may be higher, equal to, or lower than their prevalence in conventional equivalents $(31,32)$.

The aim of this review is to summarise, based on a screening of the recent literature, the information on the microbiological safety of food of animal origin produced from raw materials obtained from organic farms. As there have been a limited number of such studies carried out in Poland, the data utilised in this article are mostly from other countries.

\section{Contamination with Campylobacter}

Campylobacter is one of the main agents of bacterial gastroenteritis, usually causing self-limiting diarrhoea $(11,20)$. It is also associated with extraintestinal infections that include bacteraemia, haemolytic uraemic syndrome, reactive arthritis and meningitis (11). In 2018, the number of confirmed human campylobacteriosis cases in the European Union was 246,571, including 719 in Poland. There were 522 food-borne campylobacteriosis outbreaks in the EU with 2,335 persons involved. Two of the most common sources of these bacteria were broiler meat and unpasteurised cow's milk. The monitoring data on Campylobacter in food demonstrated the highest proportion of test-positive units to be in fresh meat from broilers $(37.5 \%)$. Such food products were also reported as one of the main sources of Campylobacter outbreaks in 2018 (13). Harvey et al. (18) described seven outbreaks caused by Campylobacter which were associated with organic raw meat and cream.

Campylobacter was present more often on freerange chicken farms than on farms with caged rearing, but the contamination level of meat was similar (32). Heuer et al. (21) and Rosenquist et al. (38) also reported higher percentages of Campylobacter prevalence on free-range farms (100\% and $54.2 \%$, respectively) than on farms using conventional poultry housing $(36.7 \%$ and $19.7 \%$, respectively). Likewise, a higher prevalence of Campylobacter was observed in antimicrobial-free swine breeding $(77.3 \%)$ than in conventional pig production (27.6\%) (42). Esteban et al. (12) demonstrated a higher incidence of Campylobacter in non-organic animal breeding than in organic, but in both types the percentages of bacteria-positive samples were similar, i.e. $76.7 \%$ and $70.6 \%$, respectively. Economou et al. (11) examined 369 raw chicken meat samples from free-range and conventional poultry farms and showed a higher prevalence of Campylobacter on the latter (29.4\%) than the former $(25 \%)$. In both types of animal production, the most common was C. jejuni $(60.4 \%$ and $53.3 \%$, respectively), followed by $C$. coli $(38.5 \%$ and $40 \%$, respectively). Wild birds and soil were considered an important source of infections for the free-range poultry farms in this study (11).

\section{Contamination with Salmonella}

Salmonellosis remains the second most commonly reported gastrointestinal infection in humans in the European Union (41). In 2018, 91,857 confirmed cases were identified, with 9,064 infections in Poland. In total, 1,580 food-borne outbreaks of salmonellosis were described. Salmonella caused $30.7 \%$ of all food-borne outbreaks of gastrointestinal infection in the EU with 11,581 humans involved. Most of these outbreaks were caused by $S$. Enteritidis and $S$. Typhimurium. The highest levels of Salmonella-positive samples were identified in poultry meat and other meat intended to be cooked before consumption (13); however, Harvey et al. (18) reported two outbreaks which were associated with organic eggs contaminated with $S$. Enteritidis and resulted in 31 infected persons.

Salmonella was present in a relatively small number of organically reared birds tested post slaughter, which may support the theory that organic animals are less susceptible to colonisation by these bacteria (32). In a study in which 595 eggs and environmental samples from farms of caged and free-range breeding hens were tested, Salmonella was found more often in conventional (11 out of $208,5.3 \%$ ) than in organic production (10 out of 387, 2.6\%). Eighteen out of all 21 Salmonella strains isolated were $S$. Typhimurium and one was $S$. Enteritidis (28). On the other hand, in another study the prevalence of Salmonella-positive pigs was higher on outdoor farms 
than on farms rearing animals in pigsheds. It was assumed that there is a risk of the presence of Salmonella in meat from such farming systems (31). Tomang et al. (41) also demonstrated that Salmonella occurred more often in pork from organic pigs $(8.3 \%)$ than in pork from non-organic animals (3.5\%), but more isolates of $S$. Enteritidis and $S$. Typhimurium were noted on conventional than on organic farms, i.e. $76.6 \%$ and $28.3 \%$ of all Salmonella isolated, respectively. Furthermore, Hoogenboom et al. (22) detected Salmonella in $27 \%$ of samples obtained from organic pig farms, which was comparable with the analogous data from conventional farms. They also identified Salmonella on $20 \%$ of organic dairy farms and $11 \%$ of broiler farms (22). The study of Fossler et al. (15) showed a similar prevalence of Salmonella on organic and conventional dairy farms (5.2\% and 4.8\%, respectively). Esteban et al. (12) demonstrated an even lower percentage of Salmonella on poultry farms under both systems, i.e. $2.9 \%$ (organic) and $1.7 \%$ (conventional).

\section{Contamination with Shiga toxin-producing Escherichia coli}

Pathogenic E. coli, especially E. coli O157:H7, are food-borne pathogens that cause outbreaks of haemorrhagic colitis, which often leads to haemolytic uraemic syndrome in children and the elderly (37). In 2018, 8,161 cases of STEC infection in humans were confirmed in the EU, but only 5 individuals were identified as infected with the pathogen in Poland. A total of 43 food-borne STEC outbreaks affecting 381 humans were reported, mainly caused by bovine meat and milk products (13). Three outbreaks due to E. coli O157:H7 were reported in the USA associated with organic raw meat and cream, which resulted in 18 persons infected (18). In Denmark in 2003-2004, 25 people were infected with STEC O157 after consumption of organic milk from a small dairy (27).

Equal or lower rates of STEC prevalence were detected in livestock from organic farms compared to animals from conventional ones. According to Lucke (32), the differences in the prevalence of these bacteria were associated with the feeding of animals. It has been supposed that the greater amount of roughage in the livestock diet in organic farming may reduce the $E$. coli level in the colon (32). Similar rates of incidence of E. coli $\mathrm{O} 157: \mathrm{H} 7$ in beef from organic and conventional farms were found by Reinstein et al. (37). In their study, the prevalence of these bacteria was $14.8 \%$ in beef from organic and $14.2 \%$ in beef not from organic production. The results obtained by Cho et al. (7) showed a greater difference - E. coli $\mathrm{O} 157$ was detected in $8.4 \%$ of samples from organic dairy cattle farms and in $3 \%$ from conventional farms. Hoogenboom et al. (22) showed the presence of this pathogen on 2 out of 10 organic dairy farms. There are also studies that demonstrated the absence of STEC, including E. coli $\mathrm{O} 157$, on organic cattle and poultry farms $(12,34,47)$.

\section{Contamination with Listeria monocytogenes}

Another important food-borne pathogen is L. monocytogenes, which is responsible for listeriosis, a disease especially dangerous for infants, pregnant women, the elderly, and immunosuppressed individuals (1). Listeriosis is characterised by high mortality; thus, the presence of these microorganisms is monitored in food and food production environments $(19,26)$. In 2018, 2,549 confirmed human cases of listeriosis in the EU were reported by 28 member states (128 in Poland), of which $15.6 \%$ were fatal. This makes listeriosis one of the most serious food-borne diseases in the EU. L. monocytogenes was detected in ready-to-eat food made of bovine meat and much less frequently in meat from other animal species, and in milk products (13). Pradhan et al. (36) reported two cases of human infection related to raw organic milk consumption.

L. monocytogenes was detected on both organic and conventional poultry farms at similar levels of $26.5 \%$ and $26.7 \%$, respectively (12). Most of the bacteria were of the $4 \mathrm{~b}$ serogroup, which is responsible for the majority of human listeriosis outbreaks $(12,48)$. Similarly, Gücükoğlu et al. (16) demonstrated the presence of L. monocytogenes in 60 out of $240(25 \%)$ organic chicken meat samples. Most of the isolates were of the $1 / 2$ a serogroup (71.9\%), followed by $1 / 2 \mathrm{~b}(21.8 \%)$, $4 \mathrm{~b}(4.2 \%)$ and $1 / 2 \mathrm{c}(2.1 \%)(16)$. The $1 / 2$ a serogroup is considered to be the most prevalent in food among all L. monocytogenes identified (48). Schwaiger et al. (39), who tested almost 1,000 swab samples as well as eggs on various kinds of chicken farms, did not detect L. monocytogenes at all. Other Listeria species such as L. innocua and L. seeligeri were noted on conventional and organic farms at the levels of $1.8 \%$ and $1.3 \%$, respectively (39). Likewise, no significant differences in the prevalence of Listeria spp. were found by Jones et al. (28) between eggs or in the farm environments of flocks of caged layers and those of free-range layers. Detection of L. monocytogenes was achieved in 2 out of 7 Listeria-positive samples among 249 samples tested (28). Pesavento et al. (34) demonstrated the absence of L. monocytogenes in 300 samples of eggs collected from organic and free-range farms.

\section{Contamination with Staphylococcus aureus}

Staphylococcus bacteria, especially $S$. aureus, are involved in food-borne infections of humans and in food poisoning (43). The disease caused by staphylococci is due to the production of enterotoxins during bacterial growth (34). In $2018,8.4 \%$ of 15,598 food samples were reported as Staphylococcus spp.-positive in 15 European countries. Furthermore, 46 out of 3,908 such samples $(1.2 \%)$ were contaminated with staphylococcal enterotoxins (13).

The occurrence of $S$. aureus is common in farm environments as well as in meat or eggs, depending on 
the farm's production profile. On organic farms, the bacteria occur less frequently. In microbiological analyses of eggs deriving from organic and free-range chicken farms, $S$. aureus was detected in 4 out of 300 (1.3\%) samples (34), whereas eggs from conventional farms were positive for these bacteria at the level of $10.5 \%$ (23 out of 220 samples) (35). Carrel et al. (5) tested meat from various retailers and also demonstrated a lower prevalence of $S$. aureus in organic samples $(16.7 \%)$ compared to those from conventional production (35.1\%). Similarly, Haskell et al. (17) detected $S$. aureus at a higher level in raw poultry meat from conventional farms $(27.4 \%)$ than in this meat from antibiotic-free farms (13\%). Also in the case of dairy products, the percentage of $S$. aureus-positive samples was higher for the non-organic $(44.8 \%)$ than for the organic products $(31 \%)(30)$. There are also studies that demonstrated the complete absence of $S$. aureus in livestock raised in an ecology and welfare-promoting system (10).

\section{Contamination with antimicrobial resistant bacteria}

One of the most important problems in terms of food safety and public health is the occurrence of antimicrobial-resistant bacteria (32). It seems that the restriction on the therapeutic use of antibiotics in organic animal production lowers the incidence of antimicrobial resistance in bacterial isolates from organically farmed animals compared to those bred in an unrestricted system (46). Most studies showed a low prevalence of methicillin-resistant $S$. aureus (MRSA) in livestock on organic farms as well as in such poultry and pork (32). The incidence of MRSA may present a real problem and a risk to human health (44). Van de Vijver et al. (44) examined approximately half of all organic pig farms in the Netherlands and detected MRSA on $20.8 \%$ of them. On conventional farms, MRSA was more widespread, noted in up to $70.1 \%$ of herds. It suggests that antibiotic usage contributed significantly to the higher MRSA prevalence in herds reared intensively (4). The observations of Haskell et al. (17) confirmed these findings and showed a higher level of MRSA in meat from nonorganic farms $(15.7 \%)$, while in antibiotic-free farmed meat MRSA was not detected at all. Antimicrobial resistance of Campylobacter also occurred less commonly in organic herds than in conventional breeding. It was found that $45 \%$ of Campylobacter isolates from organic pig farms showed antimicrobial resistance compared to $80 \%$ from farms not using organic methods $(22,32)$. Thakur and Gebreyes (42) also demonstrated a higher prevalence of erythromycin and tetracycline resistant Campylobacter isolates from conventional pig farms (77\% and $83.4 \%$, respectively) than in those from organic farming $(34.5 \%$ and $56.2 \%$, respectively). However, the presence of Enterobacteriaceae bacteria, in particular E. coli, with genes encoding extendedspectrum $\beta$-lactamases (ESBL) was similar on both organic and conventional farms (32). Stuart et al. (40) detected ESBL-producing microorganisms in $100 \%$ of chicken meat samples from non-organic and in $84 \%$ of samples from organic farms. The rates of resistance to trimoxazole, ciprofloxacin and tobramycin were the same in both farming systems and were $56 \%, 14 \%$, and $2 \%$, respectively. Nevertheless, bacteria resistant to tetracycline were more prevalent on conventional (73\%) than organic (46\%) holdings (40). Millman et al. (33), who examined chickens from various types of farming including conventional and organic for the presence of antimicrobial resistant $E$. coli, demonstrated comparable rates in both categories. However, resistance to the antimicrobials such as cefazolin and ampicillin was detected more often in the bacteria isolated from chickens from the organic farms (43\% and 33\%, respectively) than in bacteria from intensively farmed chickens (30\% and $24 \%$, respectively). On the other hand, resistance to gentamicin, ampicillin-sulbactam and trimethoprim-sulfamethoxazole was more frequent in conventionally reared chickens $(24 \%, 18 \%$, and $9 \%$, respectively) than in organic poultry $(13 \%, 13 \%$, and $0 \%$, respectively) (33). Similarly, the prevalence of antimicrobial resistant Salmonella was significantly lower on organic pig farms $(54.7 \%)$ compared to isolates from conventional farming $(97.9 \%)(41)$. The isolates were most often resistant to tetracycline $(97.9 \%$ vs 54.7\%), followed by ampicillin (95.7\% vs 39.6\%), gentamycin $(76.6 \%$ vs $15.1 \%)$ and streptomycin $(59.6 \%$ vs $54.7 \%$ ). However, resistance to ceftiofur, cephalothin and colistin was observed only in Salmonella isolated from organic farms $(15.1 \%, 15.1 \%$ and $1.9 \%$ of strains, respectively) (41).

The incidence of antibiotic resistance is lower in organic production than in the conventional approach. The maintenance of animal health in organic farming is mainly based on prophylaxis, through management factors such as hygiene measures and lower livestock densities (14). The less frequent occurrence of antimicrobial resistant bacteria in free-range livestock may also be due to the more restrictive use of antibiotics. Moreover, animals in such farming systems demonstrated a higher resistance to colonisation by some of the bacterial pathogens (32).

\section{Conclusions and perspectives}

The above data relate mainly to livestock and food production environments. As very few studies focus on pathogens from organic food products, especially readyto-eat food, further studies on organic food safety are necessary. Consumer interest in organic food is growing. Thus, the presence of pathogenic bacteria in this kind of food, especially those belonging to the species referred to in the present article, may be a potential problem and cause a public health risk. Therefore, further studies are needed to assess the microbiological safety of food produced from organically farmed animals. 
Conflict of Interests Statement: The authors declare that there is no conflict of interests regarding the publication of this article.

Financial Disclosure Statement: This study was supported by the Polish Ministry of Science and Higher Education within the statutory activity of the National Veterinary Research Institute.

\section{Animal Rights Statement: None required.}

\section{References}

1. Alonso-Hernando A., Prieto A., García-Fernández C., AlonsoCalleja C., Capita R.: Increase over time in the prevalence of multiple antibiotic resistance among isolates of Listeria monocytogenes from poultry in Spain. Food Control 2012, 23, 37-41, doi: 10.1016/j.foodcont.2011.06.006.

2. Bacanli M., Başaran N.: Importance of antibiotic residues in animal food. Food Chem Toxicol 2019, 125, 462-466, doi: 10.1016/j.fct.2019.01.033.

3. Bintis T.: Microbial pollution and food safety. AIMS Microbiol 2018, 4, 377-396, doi: 10.3934/microbiol.2018.3.377.

4. Broens E.M., Graat E.A., Van der Wolf P.J., Van de Giessen A.W., De Jong M.C.: Prevalence and risk factor analysis of livestock associated MRSA-positive pig herds in the Netherlands. Prev Vet Med 2011, 102, 41-49, doi: 10.1016/j.prevetmed.2011.06.005.

5. Carrel M., Zhao C., Thapaliya D., Bitterman P., Kates A.E., Hanson B.M., Smith T.C.: Assessing the potential for raw meat to influence human colonization with Staphylococcus aureus. Sci Rep 2017, 7, 10848, doi: 10.1038/s41598-017-11423-6.

6. Chen J., Ying G-G., Deng W-J.: Antibiotic Residues in Food: Extraction, Analysis, and Human Health Concerns. J Agric Food Chem 2019, 67, 7569-7586, doi: 10.1021/acs.jafc.9b01334.

7. Cho S., Bender J.B., Diez-Gonzalez F., Fossler C.P., Hedberg C.W., Kaneene J.B., Ruegg P.L., Warnick L.D., Wells S.J.: Prevalence and characterization of Escherichia coli $\mathrm{O} 157$ isolates from Minnesota dairy farms and county fairs. J Food Prot 2006, 69, 252-259, doi: 10.4315/0362-028X-69.2.252.

8. Commission of the European Communities: Commission Regulation (EC) No 889/2008 of 5 September 2008 laying down detailed rules for the implementation of Council Regulation (EC) No 834/2007 on organic production and labelling of organic products with regard to organic production, labelling and control. OJ L 2008, 250, 51, 18/09/2008, 1-84.

9. Council of the European Union: Council Regulation (EC) No $834 / 2007$ of 28 June 2007 on organic production and labelling of organic products and repealing Regulation (EEC) No 2092/91. OJ L 2007, 189, 50, 20/7/2007, 1-23.

10. Cuny C., Friedrich A.W., Witte W.: Absence of livestockassociated methicillin-resistant Staphylococcus aureus clonal complex CC398 as a nasal colonizer of pigs raised in an alternative system. Appl Environ Microbiol 2012, 78, 1296-1297, doi: 10.1128/AEM.07260-11.

11. Economou V., Zisides N., Gousia P., Petsios S., Sakkas H., Soultos N., Papadopoulou C.: Prevalence and antimicrobial profile of Campylobacter isolates from free-range and conventional farming chicken meat during a 6-year survey. Food Control 2015, 56, 161-168, doi: 10.1016/j.foodcont.2015.03.022.

12. Esteban J.I., Oporto B., Aduriz G., Juste R.A., Hurtado A.: A survey of food-borne pathogens in free-range poultry farms. Int J Food Microbiol 2008, 123, 177-182, doi: 10.1016/j.ijfoodmicro.2007.12.012.

13. European Food Safety Agency and European Centre for Disease Prevention and Control: The European Union One Health 2018 zoonoses report. EFSA J 2019, 17, 5926, doi: $10.2903 /$ j.efsa.2019.5926.
14. European Parliamentary Research Service Scientific Foresight Unit (STOA): Human health implications of organic food and organic agriculture. Publications Office of the European Union, Luxembourg, 2017, doi: 978-92-846-0395-4.

15. Fossler C.P., Wells S.J., Kaneene J.B., Ruegg P.L., Warnick L.D., Eberly L.E., Godden S.M., Halbert L.W., Campbell A.M., Bolin C.A., Geiger Zwald A.M.: Cattle and environmental sample-level factors associated with the presence of Salmonella in a multi-state study of conventional and organic dairy farms. Prev Vet Med 2005, 67, 39-53, doi: 10.1016/j.prevetmed.2004.10.005.

16. Gücükoğlu A., Çadırcı Ö., Terzi Gülel G., Uyanık T., Kanat S.: Serotyping and antibiotic resistance profile of Listeria monocytogenes isolated from organic chicken meat. Kafkas Univ Vet Fak Derg 2020, 26, 499-505, doi: 10.9775/kvfd.2019.23638.

17. Haskell K.J., Schriever S.R., Fonoimoana K.D., Haws B., Hair B.B., Wienclaw T.M., Holmstead J.G., Barboza A.B., Berges E.T., Heaton M.J., Berges B.K.: Antibiotic resistance is lower in Staphylococcus aureus isolated from antibiotic-free raw meat as compared to conventional raw meat. PLoS One 2018, 13, e0206712, doi: 10.1371/journal.pone.0206712.

18. Harvey R.R., Zakhour C.M., Gould L.H.: Foodborne disease outbreaks associated with organic foods in the United States. J Food Prot 2016, 79, 1953-1958, doi: 10.4315/0362-028X.JFP16-204.

19. Henriques A.R., Cristino J.M., Fraqueza M.J.: Genetic characterization of Listeria monocytogenes isolates from industrial and retail ready-to-eat meat-based foods and their relationship with clinical strains from human listeriosis in Portugal. J Food Prot 2017, 80, 551-560, doi: 10.4315/0362028X.JFP-16-310.

20. Heredia N., García S.: Animals as sources of food-borne pathogens: A review. Anim Nutr 2018, 4, 250-255, doi: 10.1016/j.aninu.2018.04.006

21. Heuer O.E., Pedersen K., Andersen J.S., Madsen M.: Prevalence and antimicrobial susceptibility of thermophilic Campylobacter in organic and conventional broiler flocks. Lett Appl Microbiol 2001, 33, 269-274, doi: 10.1046/j.1472-765X.2001.00994.x.

22. Hoogenboom L.A.P., Bokhorst J.G., Northolt M.D., van de Vijver L.P.L., Broex N.J.G., Mevius D.J., Meijs J.A.C., Van der Roest J.: Contaminants and microorganisms in Dutch organic food products: a comparison with conventional products. Food Addit Contam 2008, 25, 1195-1207, doi: 10.1080/02652030802014930.

23. Jabbar A., Rehman S.U.: Microbiological evaluation of antibiotic residues in meat, milk and eggs. J Microbiol Biotechnol Food Sci 2013, 5, 2349-2354.

24. Jackson E.E., Erten E.S., Maddi N., Graham T.E., Larkin J.W., Blodgett R.J., Schlesser J.E., Reddy R.M.: Detection and enumeration of four foodborne pathogens in raw commingled silo milk in the United States. J Food Prot 2012, 75, 1382-1393, doi: 10.4315/0362-028X.JFP-11-548.

25. Jacob M.E., Fox J.T., Reinstein S.L., Nagaraja T.G.: Antimicrobial susceptibility of foodborne pathogens in organic or natural production systems: an overview. Foodborne Path Dis 2008, 5, 721-730, doi: 10.1089/fpd.2008.0095.

26. Jamali H., Paydar M., Ismail S., Looi C.Y., Wong W.F., Radmehr B., Abedini A.: Prevalence, antimicrobial susceptibility and virulotyping of Listeria species and Listeria monocytogenes isolated from open-air fish markets. BMC Microbiol 2015, 15, 144, doi: 10.1186/s12866-015-0476-7.

27. Jensen C., Ethelberg S., Gervelmeyer A., Nielsen E.M., Olsen K.E., Mølbak K.: First general outbreak of Verocytotoxin-producing Escherichia coli O157 in Denmark. Euro Surveill 2006, 11, 55-58, doi: 10.2807/esm.11.02.00597-en.

28. Jones D.R., Anderson K.E., Guard J.Y.: Prevalence of coliforms, Salmonella, Listeria, and Campylobacter associated with eggs and the environment of conventional cage and free-range egg production. Poult Sci 2012, 91, 1195-1202.

29. Kijlstra A., Meerburg B.G., Bos A.P.: Food safety in free-range and organic livestock systems: risk management and responsibility. J Food Prot 2009, 72, 2629-2637, doi: 10.3382/ps.2011-01795. 
30. Kukułowicz A.: Comparison of microbiological quality of milk products from organic and conventional production. Rocz Naukowe Stow Ekonomistów Rol Agrobiz 2018, 20, 147-153, doi: 10.5604/01.3001.0012.7744.

31. Leifert C., Ball K., Volakakis N., Cooper J.M.: Control of enteric pathogens in ready-to-eat vegetable crops in organic and 'low input' production systems: a HACCP-based approach. J Appl Microbiol 2008, 105, 931-950, doi: 10.1111/j.1365-2672.2008. 03794.x.

32. Lucke F.K.: Microbiological safety of organic and conventional foods. Foodbalt 2017 conference paper, doi: 10.22616/foodbalt. 2017.003.

33. Millman J.M., Waits K., Grande H., Marks A.R., Marks J.C., Price L.B., Hungate B.A.: Prevalence of antibiotic-resistant E. coli in retail chicken: comparing conventional, organic, kosher, and raised without antibiotics. F1000Res 2013, 2, 155, 1-14, doi: 10.12688/f1000research.2-155.v2.

34. Pesavento G., Calonico C., Runfola M., Lo Nostro A.: Free-range and organic farming: Eggshell contamination by mesophilic bacteria and unusual pathogens. J Appl Poult Res 2017, 26, 509-517, doi: 10.3382/japr/pfx023.

35. Pondit A., Haque Z.F., Al Momen Sabuj A., Khan M.S.R., Saha S. Characterization of Staphylococcus aureus isolated from chicken and quail eggshell. J Adv Vet Anim Res 2018, 5, 466-471, doi: 10.5455/javar.2018.e300.

36. Pradhan A.K., Pang H., Mishra A.: Chapter 6 - Foodborne disease outbreaks associated with organic foods: Animal and plant products. In: Safety and Practice for Organic Food, edited by D. Biswas and S.A. Micallef, Academic Press, Cambridge, 2019, pp. 135-150, doi: 10.1016/B978-0-12-812060-6.00006-4.

37. Reinstein S., Fox J.T., Shi X., Alam M.J., Renter D.G., Nagaraja T.G.: Prevalence of Escherichia coli O157:H7 in organically and naturally raised beef cattle. Appl Environ Microbiol 2009, 75, 5421-5423, doi: 10.1128/AEM.00459-09.

38. Rosenquist H., Boysen L., Krogh A.L., Jensen A.N., Nauta M.: Campylobacter contamination and the relative risk of illness from organic broiler meat in comparison with conventional broiler meat. Int J Food Microbiol 2013, 162, 226-230, doi: 10.1016/j.ijfoodmicro.2013.01.022.

39. Schwaiger K., Schmied E-M.V., Bauer J.: Comparative analysis on antibiotic resistance characteristics of Listeria spp. and Enterococcus spp. isolated from laying hens and eggs in conventional and organic keeping systems in Bavaria, Germany.
Zoonoses Public Health 2010, 57, 171-180, doi: 10.1111/j.18632378.2008.01229.x.

40. Stuart J.C., van den Munckhof T., Voets G., Scharringa J., Fluit A., Leverstein-Van Hall M.: Comparison of ESBL contamination in organic and conventional retail chicken meat. Int J Food Microbiol 2012, 154, 212-214, doi: 10.1016/j.ijfoodmicro. 2011.12.034

41. Tamang M.D., Gurung M., Nam H.M., Moon D.C., Kim S.R., Jang G.C., Jung D.Y., Jung S.C., Park Y.H., Lim S.K.: Prevalence and characterization of Salmonella in pigs from conventional and organic farms and first report of $S$. serovar 1,4,[5],12:i:- from Korea. Vet Microbiol 2015, 178, 119-124, doi: 10.1016/j.vetmic. 2015.05.005.

42. Thakur S., Gebreyes W.A.: Prevalence and antimicrobial resistance of Campylobacter in antimicrobial-free and conventional pig production systems. J Food Prot 2005, 68, 2402-2410, doi: 10.4315/0362-028X-68.11.2402.

43. Ünal N., Askar S., Macun H.C., Sakarya F., Altun B., Yıldırım M.: Panton-Valentine leukocidin and some exotoxins of Staphylococcus aureus and antimicrobial susceptibility profiles of staphylococci isolated from milks of small ruminants. Trop Anim Health Prod 2012, 44, 573-579, doi: 10.1007/s11250-011-9937-7.

44. van de Vijver L.P.L., Tulinski P., Bondt N., Mevius D., Verwer C.: Prevalence and molecular characteristics of methicillin-resistant Staphylococcus aureus (MRSA) in organic pig herds in the Netherlands. Zoonoses Public Health 2014, 61, 338-345, doi: 10.1111/zph.12076.

45. Willer H., Lernoud J.: The World of Organic Agriculture Statistics and Emerging Trends 2019, edited by H. Willer, J. Lernoud, IFOAM - Organics International, Rheinbreitbach, Germany, 2019, doi: 978-3-03736-118-4.

46. Winter C.K., Davis S.F.: Organic foods. J Food Sci 2006, 71 , 117-124, doi: 10.1111/j.1750-3841.2006.00196.x.

47. Zhang J., Wall S.K., Xu L., Ebner P.D.: Contamination rates and antimicrobial resistance in bacteria isolated from "grass-fed" labeled beef products. Foodborne Path Dis 2010, 7, 1331-1336, doi: $10.1089 / \mathrm{fpd} .2010 .0562$

48. Zhang Y., Yeh E., Hall G., Cripe J., Bhagwat A.A., Meng J.: Characterisation of Listeria monocytogenes isolated from retail foods. Int $\mathrm{J}$ Food Microbiol 2007, 113, 47-53, doi: 10.1016/j.ijfoodmicro.2006.07.010 